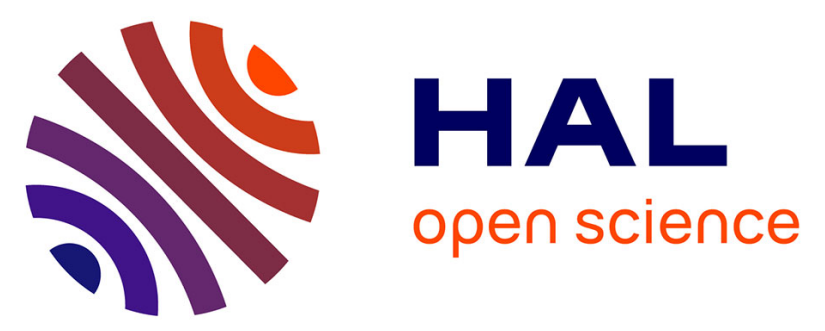

\title{
Electrostatic Waves with Rapid Frequency Shifts in the Solar Wind Sunward of 1/3 AU
}

\author{
Lily Kromyda, David M. Malaspina, Robert E. Ergun, Jasper Halekas, \\ Michael L. Stevens, Jennifer L. Verniero, Daniel Vech, Alexandros Chasapis, \\ Stuart D. Bale, John W. Bonnell, et al.
}

\section{To cite this version:}

Lily Kromyda, David M. Malaspina, Robert E. Ergun, Jasper Halekas, Michael L. Stevens, et al.. Electrostatic Waves with Rapid Frequency Shifts in the Solar Wind Sunward of 1/3 AU. vEGU21, 2021, Online, France. 10.5194/egusphere-egu21-16103 . insu-03559280

\section{HAL Id: insu-03559280 \\ https://hal-insu.archives-ouvertes.fr/insu-03559280}

Submitted on 7 Feb 2022

HAL is a multi-disciplinary open access archive for the deposit and dissemination of scientific research documents, whether they are published or not. The documents may come from teaching and research institutions in France or abroad, or from public or private research centers.
L'archive ouverte pluridisciplinaire HAL, est destinée au dépôt et à la diffusion de documents scientifiques de niveau recherche, publiés ou non, émanant des établissements d'enseignement et de recherche français ou étrangers, des laboratoires publics ou privés.

\section{(c)(1)}

Distributed under a Creative Commons Attribution| 4.0 International License 
EGU21-16103

https://doi.org/10.5194/egusphere-egu21-16103

EGU General Assembly 2021

(c) Author(s) 2022. This work is distributed under

the Creative Commons Attribution 4.0 License.

\section{Electrostatic Waves with Rapid Frequency Shifts in the Solar Wind Sunward of $1 / 3 \mathrm{AU}$}

Lily Kromyda ${ }^{1}$, David M. Malaspina ${ }^{1}$, Robert E. Ergun ${ }^{1}$, Jasper Halekas ${ }^{2}$, Michael L. Stevens ${ }^{3}$, Jennifer L. Verniero ${ }^{4}$, Daniel Vech ${ }^{1}$, Alexandros Chasapis ${ }^{1}$, Stuart D. Bale ${ }^{4}$, John W. Bonnell ${ }^{4}$, Thierry Dudok de Wit ${ }^{5}$, Keith Goetz ${ }^{6}$, Katherine Goodrich ${ }^{4}$, Peter R. Harvey ${ }^{4}$, Robert J. MacDowall ${ }^{7}$, Marc Pulupa ${ }^{4}$, Anthony W. Case ${ }^{3}$, Justin C. Kasper ${ }^{8}$, Kelly E. Korreck ${ }^{3}$, Davin E. Larson ${ }^{4}$, and the Lily Kromyda*

${ }^{1}$ University of Colorado Boulder, Laboratory for Atmospheric and Space Physics, Astrophysics and Planetary Sciences, United States of America (glkromyda@gmail.com)

${ }^{2}$ University of lowa, lowa City, IA, USA

${ }^{3}$ Harvard-Smithsonian Center for Astrophysics, Cambridge, MA, USA

${ }^{4}$ Space Sciences Laboratory, University of California, Berkeley, CA, USA

${ }^{5}$ LPC2E, CNRS, and University of Orleans, Orleans, France

${ }^{6}$ School of Physics and Astronomy, University of Minnesota, Minneapolis, MN, USA

${ }^{7}$ NASA Goddard Space Flight Center, Greenbelt, MD, USA

${ }^{8}$ University of Michigan, Ann Arbor, MI, USA

*A full list of authors appears at the end of the abstract

During its first five orbits, the FIELDS plasma wave investigation on board Parker Solar Probe (PSP) has observed a multitude of plasma waves, including electrostatic whistler and electron Bernstein waves (Malaspina et al. 2020), sunward propagating whistlers (Agapitov et al. 2020), ion-scale electromagnetic waves (Verniero et al. 2020, Bowen et al. 2020) and Alfven, slow and fast mode waves (Chaston et al. 2020).

The importance of these waves lies in their potential to redistribute the energy of the solar wind among different particles species (wave-particle interactions) or different types of waves (wavewave interactions). The abundance of waves and instabilities observed with PSP points to their central role in the regulation of this energy exchange.

Here we present first observations of an intermittent, electrostatic and broadband plasma wave that is ubiquitous in the range of distances that PSP has probed so far. A unique feature of these waves (FDWs) is a frequency shift that occurs on millisecond timescales. In the frame of the spacecraft, FDWs usually appear between the electron cyclotron and electron plasma frequencies.

We develop a detection algorithm that identifies the FDWs in low cadence spectra. We analyze them using various statistical techniques. We establish their phenomenology and compare the magnetic fluctuations of the background magnetic field at times of FDWs and at times without FDWs. We establish their polarization with respect to the background magnetic field and search 
for correlations with various plasma parameters and features in the electron, proton and alpha particle distribution moments. We also investigate possible plasma wave modes that could be responsible for the growth of FDWs and the instability mechanisms that could be generating them.

Lily Kromyda*(1), David M. Malaspina ${ }^{(1,2)}$, Robert E. Ergun ${ }^{(1,2)}$, Jasper Halekas ${ }^{(3)}$, Michael L. Stevens ${ }^{(4)}$, Jennifer Verniero ${ }^{(5)}$, Alexandros Chasapis ${ }^{(2)}$, Daniel Vech ${ }^{(2)}$, Stuart D. Bale ${ }^{(5,6)}$, John W. Bonnell ${ }^{(5)}$, Thierry Dudok de Wit ${ }^{(7)}$, Keith Goetz ${ }^{(8)}$, Katherine Goodrich ${ }^{(5)}$, Peter R. Harvey ${ }^{(5)}$, Robert J. MacDowall ${ }^{(9)}$, Marc Pulupa ${ }^{(5)}$, Anthony W. Case ${ }^{(4)}$, Justin C. Kasper ${ }^{(10)}$, Kelly E. Korreck ${ }^{(4)}$, Davin Larson $^{(5)}$, Roberto Livi ${ }^{(5)}$, Phyllis Whittlesey ${ }^{(5)}$

(1) Astrophysical and Planetary Sciences Department, University of Colorado, Boulder, CO, USA

(2) Laboratory for Atmospheric and Space Physics, University of Colorado, Boulder, CO, USA

(3) University of lowa, lowa City, IA, USA

(4) Harvard-Smithsonian Center for Astrophysics, Cambridge, MA, USA

(5) Space Sciences Laboratory, University of California, Berkeley, CA, USA

(6) Physics Department, University of California, Berkeley, CA, USA

(7) LPC2E, CNRS, and University of Orleans, Orleans, France

(8) School of Physics and Astronomy, University of Minnesota, Minneapolis, MN, USA

(9) NASA Goddard Space Flight Center, Greenbelt, MD, USA

(10) University of Michigan, Ann Arbor, MI, USA

Lily Kromyda: additional co-authors to the list above Roberto Livi, 4, rlivi@ssl.berkeley.edu Phyllis L. Whittlesey, 4, phyllisw@ssl.berkeley.edu 